\title{
Strategizing with Hardware Rich Open Source Ecosystems
}

ISSN: 2183-0606

(CC BY 3.0)

Vol. $9,2(2021)$

p. $1-20$

AM: May $/ 2021$

SM: Jan $/ 2020$

\author{
Hervé Legenvre ${ }^{1}$, Ari-Pekka Hameri ${ }^{2}$, and Pietari Kauttu ${ }^{3}$ \\ ${ }^{1}$ EIPM - European Institute of Purchasing Management, France | hlegenvre@eipm.org \\ ${ }^{2}$ Faculty of Business and Economics (HEC) | ahameri@unil.ch \\ ${ }^{3}$ CERN/HIP-TUNI, Switzerland | pietari.kauttu@cern.ch
}

\begin{abstract}
Firms increasingly adopt open strategies to develop and deploy complex systems that combine software and hardware. Such strategies require the development of large ecosystems that coalesce the innovation capabilities of hundreds of firms across different industries. The present paper aims at understanding how different types of (1) open strategies, (2) ecosystem governance, and (3) degree of openness in complex systems relate to each other. Furthermore, we help decision makers assess the benefits and challenges associated with creating or joining such ecosystems. To do this, we perform a comparative analysis of six major hardware-rich open source ecosystems that aim at scaling up complex innovative solutions. Our findings suggest that an upstream strategy aimed at replacing supplier proprietary design with open substitutes requires a democratic governance and a degree of openness that maximize the attractiveness of the ecosystem. Also, we suggest that a downstream strategy that aims at carving a space in new markets requires an autocratic governance and degree of openness that allow to jointly attract partners and capture value.
\end{abstract}

Keywords: Strategy, Ecosystems, Open Source.

Cite paper as: Legenvre, H., Hameri, A., Kauttu, P., (2021). Strategizing with Hardware Rich Open Source Ecosystems, Journal of Innovation Management, 9(2), 1-20.; DOI: https://doi.org/10.24840/2183-0606_009.002_0003

\section{Introduction}

This paper studies the interplay between different types of open strategies, different modes of ecosystem governance, and diverse degrees of openness for complex open systems. Complex open systems are increasingly common as they enable the development and implementation of digital infrastructures such as domain specific processors, data centres, Internet of things networks, autonomous driving, 5G infrastructure or smart cities. They combine proprietary and open assets coupled together thanks to standard and open interfaces. The integration of hardware within complex open systems brings ecosystem dynamics (Teece, 2018) worthy of investigation. While there is growing interest within the industry for complex open systems, research and practical guidance remain scarce. Indeed, over the past ten years, the study of open systems has focused on software, online and mobile applications (Gawer and Cusumano, 2014; Boudreau, 2010; Cennamo and Santaló, 2019) where the ecosystems consist of a platform owner and a multiplicity of complementors who offer product extensions or applications. Hardware-rich open source ecosystems coalesce a more heterogenous set of capabilities and firms than software ecosystems, and they are less likely to be steered by a single platform owner.

This paper starts by describing the emergence of hardware-rich open source ecosystems and how they differ from open source software ecosystems. Then, we review the literature on open 
systems to develop a set of questions that link the strategy, the governance, and the degree of openness within such ecosystems. Next, we perform a comparative case study analysis of six ecosystems. This leads us to describe how different types of strategy, governance, and different degrees of openness relate to each other. This allows us to reveal some patterns essential for a thorough understanding of these ecosystems. This paper also helps decision makers assess the benefits and challenges associated with creating or joining such ecosystems.

\section{Openness: a continuous evolution}

In complex systems, openness is characterised by an open architecture that integrates open software and hardware assets. An open architecture allows to mix and match diverse assets. It is characterised by standard interfaces without major restrictions and proprietary constraints (Koren et al., 2013). Standard interfaces allow to jointly achieve mass customisation (Lau et al., 2010) and economies of scale (Frandsen, 2017). Open interfaces reduce lock-in situations and opportunistic behaviours (Shapiro and Varian, 1999). Open assets include software code and hardware design that are made publicly available so that anyone can study, modify, distribute, make, and sell these assets (OSHWA, 2016). Open assets reduce investment cost and allow to build innovation and diffusion momentum for new technology (West, 2004).

\subsection{Open source software}

The term open source was coined in 1998. It emerged out of the free software movement against proprietary code. Some fierce battles have taken place between representatives from firms like Microsoft that first favoured proprietary software and the leaders of free and open source software projects such as the GNU and the Linux project (Aksulu and Wade, 2010). However, around the turn of the century/new millennium, open source software was increasingly adopted by technology leaders in Silicon Valley. For instance, IBM started to extensively support Linux in 2000. Hadoop, the big data platform, is now an open source suite of software which IBM, Facebook, Microsoft and Oracle, amongst others, have contributed to. Although for many years Microsoft was regarded as a fierce opponent to open source software, it has now fully embraced it. Indeed, in 2016, Microsoft was the largest open source contributor on GitHub, an open source development platform (Gold, 2016).

Technology firms contribute to open source software projects that are not critical to capture competitive advantages. By doing so they benefit from other firms and individuals who use, modify, and enhance this shared asset (Balka, Raasch, \& Herstatt, 2014). They also avoid dependencies on proprietary solutions while engaging and supporting a broad community of developers; an important stakeholder for them (Stam, 2009). One key event in the history of open source is the development of Android by Google using existing open source solutions (Kapoor and Agarwal, 2017). This has accelerated the development of Android and it has favoured its adoption by smartphone manufacturers who avoided license fees while being allowed to provide complementary applications. Today open source is a common strategy for software, especially in technology firms. But open assets are also becoming more common beyond the software world (Powell, 2012).

\subsection{Open source beyond software: the rise of HROSE}

Indeed, over time openness has occasionally been adopted for hardware, for biological artefact, and other types of assets (Penin, 2011). For instance, open hardware has been adopted by some scientists who want to break free from their dependence on laboratory equipment vendors who impose high prices (Pearce, 2012). However, with the ongoing digital transformation of industries 
open strategies are appearing beyond the technology sector. For instance, in the automotive sector, open strategies are becoming more common. In 2014, Tesla made its portfolio of patents available as a means of accelerating the development of the charging infrastructure for electric vehicles (Musk, 2014). The Apollo Auto initiative led by Baidu for autonomous cars has a technology architecture with both open source and proprietary components. This initiative brings together more than 120 partner companies and 12000 developers. More recently, in the summer of 2019 Waymo and Lyft released access to their data in order to create momentum around their solutions.

Over the last 10 years there has been an emergence of complex open systems that combine open and proprietary assets and include both hardware and software assets coupled together with open interfaces. These complex systems are developed and deployed by distributed networks of firms also called ecosystems where diverse firms collaborate to design the architecture and open assets for the system (Langlois and Richardson, 1992). Following Legenvre et al, (2020) we describe these ecosystems as Hardware Rich Open Source Ecosystems (HROSE).

\subsection{How does HROSE differ from open source software ecosystems?}

Complex open systems supported by ecosystems have four key characteristics that make them different from pure software systems. First, they are more complex because of the mix of multiple hardware and software components they include. This requires an architecture with standard and open interfaces. Second, quality concerns are significant for hardware. An open source silicon with a defect in the code needs to be destroyed. The code cannot be as easily updated as is the case with most software. Third, the testing and validation costs of complex open systems are high compared to open source software. Complex open systems can require extensive testing equipment, testing facilities and testing protocols. They can also require a significant data collection effort. This is the case for autonomous cars for instance as prototypes need to be driven extensively on roads to gather an immense amount of data. Finally, to innovate and generate value, HROSE govern a very heterogeneous group of interdependent firms and organisations with complementary capabilities. Firms participating in such collaborations can have diverse antecedents with open source initiatives, which can create some resistance and difficulties to adopting and implementing open strategies. (Moritz et al., 2018)

In complex systems, openness is characterised by an open architecture that integrates open software and hardware assets. An open architecture allows to mix and match diverse assets. It is characterised by standard interfaces without major restrictions and proprietary constraints (Koren et al., 2013). Standard interfaces allow to jointly achieve mass customisation (Lau et al., 2010) and economies of scale (Frandsen, 2017). Open interfaces reduce lock-in situations and opportunistic behaviours (Shapiro and Varian, 1999). Open assets include software code and hardware design that are made publicly available so that anyone can study, modify, distribute, make, and sell these assets (OSHWA, 2016). Open assets reduce investment cost and allow to build innovation and diffusion momentum for new technology (West, 2004).

\section{Three key dimensions}

The following literature review on openness establishes a framework that comprises three dimensions that characterise HROSE. It outlines two different types of open strategies: upstream and downstream; different degrees of openness from fully open to hybrid; and different types of governance - from democratic to autocratic. 


\subsection{Upstream and downstream open strategies}

Two different types of open strategies can be adopted in HROSE, following Gambardella \& von Hippel (2019), we characterise them as downstream and upstream open strategies and we build on Alexy et al., (2018) to describe them.

Alexy et al., (2018) identified two different competitive impacts of open strategies. In the first one, the company that initiates the open strategy and its competitors benefit from this initiative.

They collaborate to establish an open architecture as they value interoperability across systems and favour competition amongst assets providers to avoid lock-in situations (Ferrer, 2010; Guertin et al., 2010). They can also collaborate to develop open assets. For instance, the development of a big data platform such as Hadoop can be supported by competing firms if this does not jeopardise their respective competitive position. They create a common innovative and cost competitive infrastructure they can all benefit from. The multiplicity and diversity of contributors to such projects allow to drive costs down but also to enhance quality (Appleyard and Chesbrough, 2017). In the present paper we call this a downstream open strategy as it is used to shape the supply market. According to Alexy et al., (2018), this is likely to happen if there is a high complementarity between the participants in the ecosystems and high fixed-cost reduction opportunities.

In the second competitive impacts described by Alexy et al., (2018) the company adopting an open strategy gains a competitive advantage over its competitors. This open strategy is often adopted by innovative or entrepreneurial ventures (Baldwin 2010). The entrepreneurial firm acts as a new entrant in a market; it focuses on key assets within the architecture and leaves other firms to complement them. This is the case of Google and Android described above. Because of its openness, mobile companies have adopted Android at the expense of competing platforms. Here a company uses openness strategically to attract both clients and complementors and to eliminate competition. We call this an upstream open strategy as it is used to shape the buying market. This open strategy is applicable when fixed costs are high and when complementarities with direct competitors remain low. In the case of Android, competitors offered their own platform in which they had made significant investments.

Therefore, the first dimension of our framework is to characterise the strategy of the founder(s) of the ecosystem either as a downstream or an upstream strategy.

\subsection{Degree of openness}

Interfaces in a complex open system are without major restrictions or proprietary constraints. Openness is not a black or white concept. Systems are not fully closed or open (West, 2006; Gawer and Cusumano 2014). Some restrictions and proprietary constraints can be applied so some firms can appropriate some of the value created (West; 2003) or keep the sales of some complementary assets for themselves (Chesbrough and Appleyard, 2007; Gawer and Cusumano 2014). The degree of openness can also change over time. In a study focusing on the computer industry, West (2003) argued that market leaders initially preferred proprietary solutions to maximise their margins. But when their position was challenged, they moved to open standards and open strategies. This created de facto a hybrid situation with a mix of openness and closedness from an intellectual property point of view. Such moves are caused by three factors: (1) high R\&D cost, (2) buyer's bargaining position, (3) competition by existing open standards or open solutions, (4) an opportunity to take advantage of certain layers in the system architecture while benefiting from openness in another layer.

Furthermore, the motivation for favouring open over closed solutions has been studied by Appleyard \& Chesbrough (2017). They found that such decisions depend on the organisation's desire to either foster greater growth by attracting more partners thanks to the openness, or 
secure greater control and profit thanks to proprietary solutions. They also indicate that, at early stages in the development of an ecosystem, when there are relatively few partners and customers, open strategies attract partners at a faster rate. In later phases, as the market matures, there are fewer new partners entering the ecosystem as the focus is on moving towards a more proprietary strategy.

Therefore, the second dimension of our framework is to characterise the ecosystem's degree of openness. We will consider the share of assets that are open versus the share that remains proprietary.

\subsection{Democratic vs autocratic governance}

The architecture of an open system can be controlled by either a firm, the platform owner (Gawer and Cusumano; 2014) or by a standard body or an open source foundation (Balka, Raasch \& Herstatt, 2010). A standard body ensures that the definition of the interfaces result from a consensus and prevents opportunistic behaviours as no firm can set expensive fees to connect to the architecture. The role of an open source foundation consists in promoting and supporting the development of open assets. Whether controlled by a platform firm or curated by a foundation, the information on the interfaces and the designs of the open assets are documented and accessible so complementary assets can be developed and connected to the architecture (Zhang et al., 2017)

This creates great differences in terms of governance from one ecosystem to another. In fact, the governance of an open ecosystem can be described along a continuum varying from democratic to autocratic (de Laat, 2007). In an autocratic governance system, the leader of the ecosystem is the firm that owns and opens the architecture. It therefore keeps for itself most decisions rights. In a more democratic governance system, a more decentralized decision-making process involving ecosystem partners is prevalent.

O'Mahony (2007) identified five characteristics of open source ecosystem governance. They can be described according to their contribution to a more democratic mode of governance. The first is the extent to which decision making is independent from the sponsor(s) in the community. The second is the openness towards the use of multiple parallel and competing methods and approaches within the ecosystem. The third is the degree to which ecosystem partners have the right to represent themselves in decision making instances. The fourth is the degree of decentralisation in the decision making. The fifth is the extent to which ecosystem partners have some autonomy regarding the terms of contribution to their common work.

Therefore, the third dimension of our framework is to characterise the governance of the ecosystem along a continuum from democratic to autocratic management.

\section{Research Method}

\subsection{Methodological approach}

To study the interplay between different types of open strategies, different modes of ecosystem governance, and diverse degrees of openness for complex open ecosystems, we performed an in-depth comparative case study of six HROSE. We adopted a comparative case study approach well suited to study contemporary phenomena and to contribute to early-stage theory development (Yin, 2013). Comparative case study provides a sound foundation for generalisation (Eisenhardt, 1989) in a context where the study of the ecosystem supporting the development of a complex system rich in hardware assets is still in its infancy. For the research we selected six ecosystems that provide diversity in terms of positioning along the three dimensions of the framework we developed. Our focus on complex open ecosystems led us to consider cases with similar degrees of 
complexity, which supports comparability.

\subsection{Research Framework for conducting the analysis.}

The research framework we used for conducting the data collection and data analysis is provided below. It was developed based on the literature review on each dimension presented above. For each type of open strategy, for each degree of openness and for each type of governance, multiple pieces of evidence were identified to support data collection and analysis.

Table 1 describes our research framework for data collection and analysis.

Table 1. Research framework for data collection and analysis.

\begin{tabular}{|c|c|c|}
\hline Dimension & Type & Evidence \\
\hline \multirow[t]{2}{*}{$\begin{array}{l}\text { Open } \\
\text { strategy }\end{array}$} & Downstream & $\begin{array}{l}\text { Buying firms actively lead the ecosystem } \\
\text { Multiple contributors to the design of open assets } \\
\text { Focus on avoiding supplier lock-in } \\
\text { Focus on lowering the cost of the assets }\end{array}$ \\
\hline & Upstream & $\begin{array}{l}\text { Entrepreneurial firms actively lead the ecosystem } \\
\text { They own and open part of the asset to complementors } \\
\text { They are new entrants who focus on gaining market shares }\end{array}$ \\
\hline \multirow[t]{2}{*}{ Openness } & $\begin{array}{l}\text { High } \\
\text { degree }\end{array}$ & $\begin{array}{l}\text { High share of open assets within the open system } \\
\text { Governance rules prevent reversibility }\end{array}$ \\
\hline & $\begin{array}{l}\text { Low } \\
\text { degree }\end{array}$ & $\begin{array}{l}\text { Small share of open assets within the open system } \\
\text { Reversibility on openness is possible }\end{array}$ \\
\hline \multirow[t]{2}{*}{ Governance } & Democratic & $\begin{array}{l}\text { Decentralised decision making } \\
\text { Extensive representation of contributors in decision making } \\
\text { High autonomy of contributors regarding the contributions } \\
\text { High transparency of the governance process }\end{array}$ \\
\hline & Autocratic & $\begin{array}{l}\text { Centralised decision making } \\
\text { Limited representation of contributors in decision making } \\
\text { Low autonomy regarding the terms of contribution } \\
\text { Lack of transparency of the governance process }\end{array}$ \\
\hline
\end{tabular}

\subsection{Data collection}

During data collection, we analysed each HROSE using multiple sources of information to achieve triangulation so the validity of our findings can be ensured. For each HROSE we collected information from the following sources. 
Table 2 describes our data collection strategy.

Table 2. Data collection strategy.

News articles We used Linknovate, an information brokering firm to access for each

Press releases HROSE hundreds of news information, press releases and publications.

Other publications This allowed us to adopt a temporal bracketing approach so we could identify possible evolution over time related to the three dimensions studied. Press releases were particularly useful to assess the degree of engagement of some firms in the ecosystem. This helped us to gain information on the nature of the open strategies undertaken.

Website and We systematically looked at the website of each HROSE studied. We information paid specific attention to different sources of information reposit We studied the rules and regulations of the organisations supporting the HROSE to gain information on their governance

We also studied the intellectual property policies and the licenses adopted in each HROSE. We considered their transparency and their possible reversibility to gain information on the degree of openness for each of them.

We studied the repository of designs and software to gain information on the degree of openness of each HROSE.

We studied diverse information including annual reports, workshop reports and others.

Conference video Each HROSE organises events and videos of speakers are available online. recordings This was particularly useful to assess the degree of engagement of some of the firms in the ecosystem. Indeed, not all members are active, some might join simply to stay informed. This helped us to gain information on the nature of the open strategies undertaken and on the degree of openness of the HROSE.

Interviews

For each HROSE, we conducted between one and three interviews. Interviewees included representatives of the organisation supporting the HROSE, members of the ecosystems or industry analysts. Interviews were semi-structured and conducted in two parts. A standard part that addressed the same questions covering the three dimensions of our framework. In the second part, more specific questions were asked for each ecosystem to clarify specific points. Interviews were particularly useful to understand specific aspects of the governance mechanism of each HROSE. Most interviews lasted one hour, some of them lasted up to 90 minutes.

This rich set of information allowed us to collect a broad array of evidence and to gain confidence in our findings. For data collection, the researchers were partially involved in two of the concerned ecosystems for a few years and the six cases were documented over a one-year period through access to the multiple sources described above.

\subsection{Data analysis}

Data collection and data analysis overlapped as a means to reaching a satisfactory degree of saturation. Interestingly, this was rapidly achieved for the HROSE that exhibited a downstream 
open strategy. Representatives from organisations that support the HROSE and from firms that are involved in these ecosystems communicate extensively about the three dimensions of the framework. For the HROSE that exhibited an upstream open strategy, achieving the same level of saturation took more time, especially to clarify the governance structure. However, by talking to representatives from firms supporting the respective ecosystem or business analysts who explained to us how the initiatives were set up, we progressed rapidly, and were able to ensure saturation.

Data analysis followed a three-step iterative process. First, the most relevant source of information for each dimension of the framework was identified within the whole set of information collected. After this phase, the information was coded based on the framework of analysis presented above. The coding was first done independently by the three researchers for each HROSE. Then the researchers compared their findings. Finally, we iterated and progressed again through data collection and analysis until triangulation and saturation were achieved.

The six ecosystems studied were the following:

RISC-V provides a free open source Instruction Set Architecture enabling processor innovation. The RISC-V foundation coordinates collaboration across 235 members including Western Digital, NVDIA, NXP, Qualcomm \& Thales.

The LoRa alliance provides its members with an loT platform to connect through the LoRaWAN (long range wide-area network) protocol, products and technologies enabling mass adoption of low cost, long range machine-to-machine connectivity. This open, non-profit association has over 500 members including IBM, Microchip, Orange, Cisco, KPN, Swisscom, Semtech, Bouygues Telecom, Singtel and Proximus.

The Telecom Infra Project (TIP) initiative aims at developing open source technologies for the telecom infrastructure. Participants in TIP include Deutsche Telekom, Facebook, Telefonica, Intel, Nokia, Vodafone, BT.

The White Rabbit project focuses on the timing and control protocol for the accelerator infrastructure at CERN. Examples of industrial applications to date can be found on time and frequency transfer, time-triggered control, precise timestamping and trigger distribution. The industrial companies currently involved in White Rabbit technology commercialisation and development are: Seven Solutions, Creotech, INCAA Computers, Janz Tec, OPNT, SyncTechnology, BEEcube, D-TACQ Solutions Ltd, Ettus Research, National Instruments, N.A.T., Struck Innovative Systems, Picoquant, Sundance Multiprocessor Technology, Teledyne SP Devices, Deutche Börse, SCPTime, Meinberg, Veryx, Integrasys, GnuDD and NetTimeLogic (van der Bij, 2019).

The Apollo project develops an open source self-driving vehicle platform to catalyse the development of autonomous cars. The project has over 100 global partners including all major software and car manufacturing companies (e.g., PSA, Volvo, Ford, Honda, VW China, Intel, Microsoft, Nvidia, Infineon, Delphi, Bosch). The Apollo project mission is to develop an "Android for automated vehicles".

The Open Compute Project (OCP) serves the needs of companies interested in hyperscale data centre implementation. Partners may use or modify the designs to run their own data centre operations. The architecture is modular with continuous multiple projects running in parallel. Participating companies include Facebook, Microsoft, Goldman Sachs, IBM, Rackspace, HP, Huawei

\section{Research findings in each ecosystem}

We start to describe our Research findings by summarizing the strategy, governance, and degree of openness for each HROSE. 


\subsection{RISC-V}

RISC-V provides a free open source Instruction Set Architecture. It helps accelerate innovation and development activities by pooling resources together. As an open source solution, it reduces administrative steps and offers flexibility for accessing suppliers and capabilities. The RISC V project was initiated in 2010 at the University of California, Berkeley. The RISC-V foundation was established in 2015. Founding members were interested in developing an open source alternative to existing Instruction Set Architecture. Leaders of the ecosystem include firms which adopted the ISA in their product and some entrepreneurial firms aiming to sell services and processors that build on RISC-V From an intellectual property point of view, the Instruction Set Architecture was released under an open source BDS license. This is a permissive license allowing to build proprietary hardware solutions based on RISC-V. Complementary open source tools and software are increasingly developed and made available by ecosystem members. With regards to its governance, the ecosystem is coordinated by a foundation. Members participate in the development of the RISC-V ISA specifications and related hardware or software. Major decisions related to the future of RISC-V are taken by a board of directors who promote the ISA and protect its integrity. The RISC-V ecosystem is evolving fast with multiple initiatives across the world.

\subsection{LoRa Alliance}

The LoRa alliance provides its members with access to hardware components and software to build low power consumption network-based services for long range and high capacity applications. This alliance is adapted for solutions where objects are spread within a wide area, like animals, cars, people, houses, machines, etc. Components are certified, and the network is easy to deploy allowing quick time to market. The LoRa Alliance was founded in 2015 and is led by Semtech, which owns and publishes the LoRaWAN specification. In 2018, the LoRa Alliance had over 100 network operators in over 100 countries selling services based on LoRaWAN. LoRa uses license-free sub-gigahertz radio frequency bands, yet some of the technologies needed to deliver operational services require proprietary components and software. Semtech is in sole possession of the RF modulation specifications and they license this to hardware manufacturers. The alliance is led by Semtech Inc. with its proprietary specification and by Actility Inc., which has developed proprietary complementary solutions to Semtech. Alliance partners pay membership fees to have a say in the direction of the LoRa Alliance, whose mission is to support and promote the global adoption of the LoRaWAN standard. Some alliance partners have expressed concerns about their dependency on these two companies. There are competing ecosystems including Sigfox which operates an loT network with its own ecosystem of partners. Telecom operators are not active in this ecosystem as Sigfox operate the network. Sigfox publicly released the specifications of its radio protocol in 2019 to allow open source implementations.

\subsection{Telecom Infra Project (TIP)}

The TIP network infrastructure is intended to be "disaggregated". The benefits are assumed to include: the disaggregation of network technologies, improved geographical coverage, innovation, speed of implementation for new services and innovative procurement and business models. This is expected to diminish the dependence of network operators on traditional vendors and also for entrepreneurial firms to participate in the industry developments. Another key motivation is the establishment by leading companies of a de facto industry standard. TIP was launched in 2016 at the San Francisco "Mobile World Congress" as a consortium of companies in the telecommunications business.

A documented policy governs the IP and enforces two pathways for patent and copyright 
licensing on group participants. Contributors have 4 options in 2 categories. If a patent is at stake, they can either release it under the RAND patent license or with a royalty-free license. If the resource is copyrightable, it must be licensed with Creative Commons-4.0-International or in the public domain. Any other type of license must be presented and accepted by the chair of the group. TIP software or hardware files are hardly publicly available. TIP is organised as a standard non-profit corporation, registered in Delaware, United States, and primarily backed by Facebook in collaboration with more than 500 companies of various sizes. The board of directors must be composed of employees from sponsor companies, with no more than one representative from each company. There is a certain degree of control exercised by the companies that established the ecosystem and created the rules for the consortium.

\subsection{White Rabbit}

The White Rabbit focuses on the timing and control protocol for the accelerator infrastructure at CERN. White Rabbit (WR) technology development is primarily funded by CERN and GSI Helmholtz Center for Heavy Ion Research, but it also receives substantial contributions from other public as well as private organisations. Applications outside the field of high energy physics (HEP) basic research include telecommunications, smart grids, air traffic control and financial services. This extensive network helps the project directly and justifies the openness of WR technologies: in addition to the enhancement of collaboration among HEP facilities, WR disseminates open infrastructure technology for commercial, governmental, and educational projects. The WR project started in 2013 by a group of electronics engineers from the Beams Control department at CERN. In the past six years, the project has become an international standard for high-accuracy time distribution for digital networks, a set of open hardware licenses (CERN Open Hardware License family) for sharing design files, and a full-fledged platform for distributing open hardware projects through the CERN Open Hardware repository. The immaterial property rights are governed by CERN Open Hardware License v2. White Rabbit is one of the few entirely patent-free "Precision Time Protocol" solutions. Its documentation is freely licensed and all technologies necessary for deploying a WR-capable network (software, gateware, hardware) are open licensed. WR has a decentralised governance system where different groups or individuals from different organisations can work on modular parts of the project. This decentralisation is made possible by virtue of the CERN Open Hardware repository.

\subsection{Apollo Auto}

The Apollo open source platform includes all components needed to build an operational autonomous vehicle. This speeds up innovation, prototyping and product development. Partners benefit from a full range of software, hardware and data tools (operating systems, high-precision positioning and HD mapping services, simulation engines, clouds, algorithms, etc.) provided by the ecosystem. Since its initiation in 2017 by Baidu, a Chinese multinational technology company, the project has gradually expanded into a global community of around 12000 developers and over 100 global partners. Open source code portions and hardware specifications can be modified and open capability components accessible through an API can be replaced with proprietary implementations. These modifications can then be returned to Apollo, redistributed, and commercialised. Baidu controls the project, and any bugs that are found in the software and hardware get reported directly to Baidu, and fixes are rolled into the distribution so all platform users can benefit. Baidu keeps the possibility of selling complementary hardware and services. The project has the support of the Chinese government in terms of making regulatory exceptions for testing technologies and enhancing domestic cross industrial collaboration. 


\subsection{The Open Compute Project, OCP}

The motive is to grow an ecosystem of users and manufacturers to gain scale and speed without dependencies. OCP adopters benefit from cost reduction, power efficiency and flexibility for custom designs. The typical figures provided, in terms of energy efficiency improvement, range from $22 \%$ to $38 \%$. Capital expenditure savings of $40 \%$ \& Operational savings of up to $52 \%$ are also regularly reported. The Open compute project was initiated by Facebook in 2011 when it shared the specifications and design principles of its data centre. In 2019 membership reached about 200 companies. The Open Compute Project is based on open source principles and guidelines. Two types of OCP specification exist. The first is OCP accepted: these products comply $100 \%$ with an existing accepted specification and the design files are open source and available. The second is OCP inspired: these proprietary products comply $100 \%$ with an existing accepted specification and are available from OCP Silver, Gold or Platinum Members. The focus of the foundation is to minimise its risk by creating a broader ecosystem of OCP adopters and manufacturers. The governance is characterised by its transparency, active contribution from a diverse base of members, an inclusive decision-making process and an active steering of the ecosystem by the foundation through a system of committees and projects. Committee members and project leads are elected among the members and decisions are made on a majority basis.

The following table summarises the findings on the six ecosystems.

Table 3. Summary of the HROSE cases.

\begin{tabular}{|c|c|c|c|}
\hline Ecosystem & Strategy & Governance & Openness \\
\hline RISC-V & $\begin{array}{l}\text { Upstream strategy: } \\
\text { This enables innovation, } \\
\text { speed of development and } \\
\text { flexibility from a vendor } \\
\text { perspective. }\end{array}$ & $\begin{array}{l}\text { Rather democratic } \\
\text { governance: } \\
\text { Led by a foundation, } \\
\text { where a board of directors } \\
\text { protects the integrity of } \\
\text { the open source code. } \\
\text { Members contribute to } \\
\text { the strategic direction of } \\
\text { the foundation. }\end{array}$ & $\begin{array}{l}\text { Significant and increasing } \\
\text { degree of openness as } \\
\text { complementary open } \\
\text { extensions and tools are } \\
\text { progressively available. } \\
\text { The adoption of an open } \\
\text { source license allows } \\
\text { proprietary development. }\end{array}$ \\
\hline $\begin{array}{l}\text { LoRa } \\
\text { alliance }\end{array}$ & $\begin{array}{l}\text { Downstream strategy: } \\
\text { This facilitates the rapid } \\
\text { development of large and } \\
\text { costly infrastructure } \\
\text { projects. } \\
\text { It allows the founder of the } \\
\text { ecosystem to advance their } \\
\text { market share in the nascent } \\
\text { loT market. }\end{array}$ & $\begin{array}{l}\text { Rather autocratic } \\
\text { governance: } \\
\text { One firm owns the } \\
\text { standard and therefore } \\
\text { exerts significant control } \\
\text { over the future of the } \\
\text { standard. } \\
\text { Partners pay membership } \\
\text { fees to influence decisions } \\
\text { in the LoRa alliance that } \\
\text { promotes the standard. }\end{array}$ & $\begin{array}{l}\text { Limited degree of } \\
\text { openness. } \\
\text { There is a mix consisting } \\
\text { of a proprietary standard, } \\
\text { a few open assets and } \\
\text { complementary } \\
\text { proprietary solutions. }\end{array}$ \\
\hline $\begin{array}{l}\text { Telecom } \\
\text { Infra Project }\end{array}$ & $\begin{array}{l}\text { Upstream strategy. } \\
\text { This disaggregates and } \\
\text { opens up proprietary } \\
\text { systems. } \\
\text { It fosters innovation speed } \\
\text { and the emergence of } \\
\text { innovative business models. }\end{array}$ & $\begin{array}{l}\text { Rather democratic } \\
\text { governance } \\
\text { It is led by a foundation } \\
\text { Founding partners have } \\
\text { the largest share of } \\
\text { decision power. }\end{array}$ & $\begin{array}{l}\text { Significant and increasing } \\
\text { degree of openness. } \\
\text { There is a mix of open } \\
\text { source and proprietary } \\
\text { assets }\end{array}$ \\
\hline
\end{tabular}




\begin{tabular}{|c|c|c|c|}
\hline Ecosystem & Strategy & Governance & Openness \\
\hline $\begin{array}{l}\text { White } \\
\text { Rabbit }\end{array}$ & $\begin{array}{l}\text { Upstream strategy. } \\
\text { Favours the diffusion of the } \\
\text { technology without vendor } \\
\text { constraints. }\end{array}$ & $\begin{array}{l}\text { Democratic Governance } \\
\text { through CERN repository } \\
\text { and collaboration } \\
\text { meetings }\end{array}$ & Fully open and patent free \\
\hline Apollo Auto & $\begin{array}{l}\text { Downstream strategy: } \\
\text { This speeds up innovation, } \\
\text { prototyping and product } \\
\text { development. } \\
\text { It allows Baidu to gain } \\
\text { market shares in this } \\
\text { nascent self-driving car } \\
\text { market. }\end{array}$ & $\begin{array}{l}\text { Autocratic governance: } \\
\text { Centrally governed by a } \\
\text { single multinational } \\
\text { company. }\end{array}$ & $\begin{array}{l}\text { Limited degree of } \\
\text { openness. } \\
\text { Mix of open and } \\
\text { proprietary components. }\end{array}$ \\
\hline $\begin{array}{l}\text { The Open } \\
\text { Compute } \\
\text { Project }\end{array}$ & $\begin{array}{l}\text { Upstream strategy: } \\
\text { This allows cost reduction, } \\
\text { power efficiency through } \\
\text { innovation and flexibility on } \\
\text { the vendor side. }\end{array}$ & $\begin{array}{l}\text { Democratic Governance } \\
\text { led by a Foundation, } \\
\text { decisions are taken on a } \\
\text { majority basis. }\end{array}$ & $\begin{array}{l}\text { High degree of openness. } \\
\text { Mix of open assets and } \\
\text { proprietary capabilities } \\
\text { supportive of the } \\
\text { standard. }\end{array}$ \\
\hline
\end{tabular}

\section{Research findings from cross-cases comparisons}

We describe our learning from the case study analysis and the cross-case study comparison along the three dimensions we have used to characterise the ecosystems.

\subsection{Open Strategies}

The six ecosystems aim to accelerate the development and adoption of innovative solutions for complex systems that combine software and hardware components around a set of standard interfaces. All the ecosystems studied bring together a heterogeneous set of organisations with diverse but complementary capabilities and some common interests. Firms that join HROSE can scale up activities with limited resources, and some of the high fixed costs associated with innovation. The standard architecture allows to generate diverse customised applications and to expand the markets. The active participation of multiple industry leaders in each ecosystem makes the respective ecosystem even more attractive to other organisations.

Our findings show that each case can be easily characterised as either upstream or downstream open strategies. Some of the ecosystems studied are best described as upstream open strategy (White Rabbit, OCP, TIP, RISC-V) while others are best described as downstream open source strategy (LoRa, Apollo Auto).

In case of upstream strategies, the companies that initiate the open source strategy do not try to evict their rivals from a market. In fact, any organisation that joins an ecosystem and complies with a limited set of rules can benefit from the collective developments that have been undertaken. Upstream open source strategies always contribute to avoid dependencies on vendors by preventing opportunities to create lock-in situations. Most of the upstream open strategies studied pull resources together for design activities across firms located at different stages of the value chain (OCP, TIP, RISC-V) thus achieving high fixed cost reduction for all participating companies. Nevertheless, we found that upstream open strategies are not always led by existing buying firms (White Rabbit, RISC-V). Leaders of the RISC-V ecosystem include a mix of buying firms and entrepreneurial ventures that develop products based on an ISA that remain accessible to any member of the RISC-V foundation. White Rabbit is essentially led by researchers at the 
CERN who want the technology to be accessible for free to all without commercial concerns. Buying firms play no role here but the main motivation of the researchers is not to conquer a market.

In the case of downstream open strategies, the ecosystem's founders aim at conquering a new market (LoRa, Apollo Auto). They use openness to attract and mobilise other clients and complementors. A single founder (Apollo Auto) or a small number of founders (Lora) invest in the design of some assets that are kept proprietary while using openness to accelerate the adoption of their solution. Downstream open strategies allow their founders to challenge the market position of their rivals. However, it should be noted that the clients of the open solution can be rivals that also benefit from a reduction in high fixed development costs. For Apollo Auto, car manufacturers that compete against each other benefit from access to an open solution that reduces their upfront investments.

\subsection{Degree of openness}

Across all ecosystems, openness is used strategically to attract contributors and clients. However, the degree of openness varies from one initiative to another. Our comparative approach shows that ecosystems adopting upstream strategies favour a high degree of openness while ecosystems adopting downstream strategies have a lower degree of openness.

Ecosystems with a downstream strategy combine open and proprietary assets (LoRa, Apollo Auto). They attract clients with the possibility of rapidly benefiting from open interfaces and open assets. However, they keep some assets and some complementary services proprietary so they can capture value over time. Such ecosystems require significant investments from the founders (Apollo Auto), but they can generate significant revenue as they lock-in partners and clients thanks to the proprietary part of the open system. Therefore, although openness is often presented as a strategy that eliminates lock-ins, our findings show that downstream open strategies create such lock-ins. This is consistent with findings on platform firms (Boudreau 2010).

For upstream strategies (White Rabbit, OCP, TIP, RISC-V), a more systematic and aggressive open approach is used to attract a maximum number of partners in the ecosystem and to eliminate lock-in situations. However, in some cases (TIP, RISC-V), a mix of open source and proprietary solutions can still exist. Indeed, it can be challenging to start with a maximum numerous open interfaces and assets right from the start of the development of an ecosystem. For TIP, telecom networks are highly complex systems built on the legacy of proprietary systems, and thus various open and proprietary solutions always complement each other. For RISC-V the code of the ISA is open but designing and manufacturing a microprocessor requires the use of complementary proprietary solutions. This shows that the degree of openness is not purely a choice made by the ecosystem founders, it also depends on the scope of the overall system and on some industry characteristics. Highly complex systems with long life cycles where past investment has shaped the system architecture and the competitive landscape cannot be easily disaggregated and opened.

\subsection{Governance}

Governance is vertically structured in all cases except for one (White Rabbit). Some of these ecosystems have adopted a democratic governance organised around a foundation (TIP, OCP, RISC-V) while others can adopt a more autocratic governance style (Apollo Auto, LoRa) and one is even led by a single firm (Apollo Auto). Our comparative approach shows that ecosystems adopting upstream strategies are more democratic while ecosystems adopting downstream strategies are more autocratic. The extremes in our sample are the basic research spirited White Rabbit and the strictly centrally controlled Apollo Auto. Other decision factors can influence governance. Indeed, 


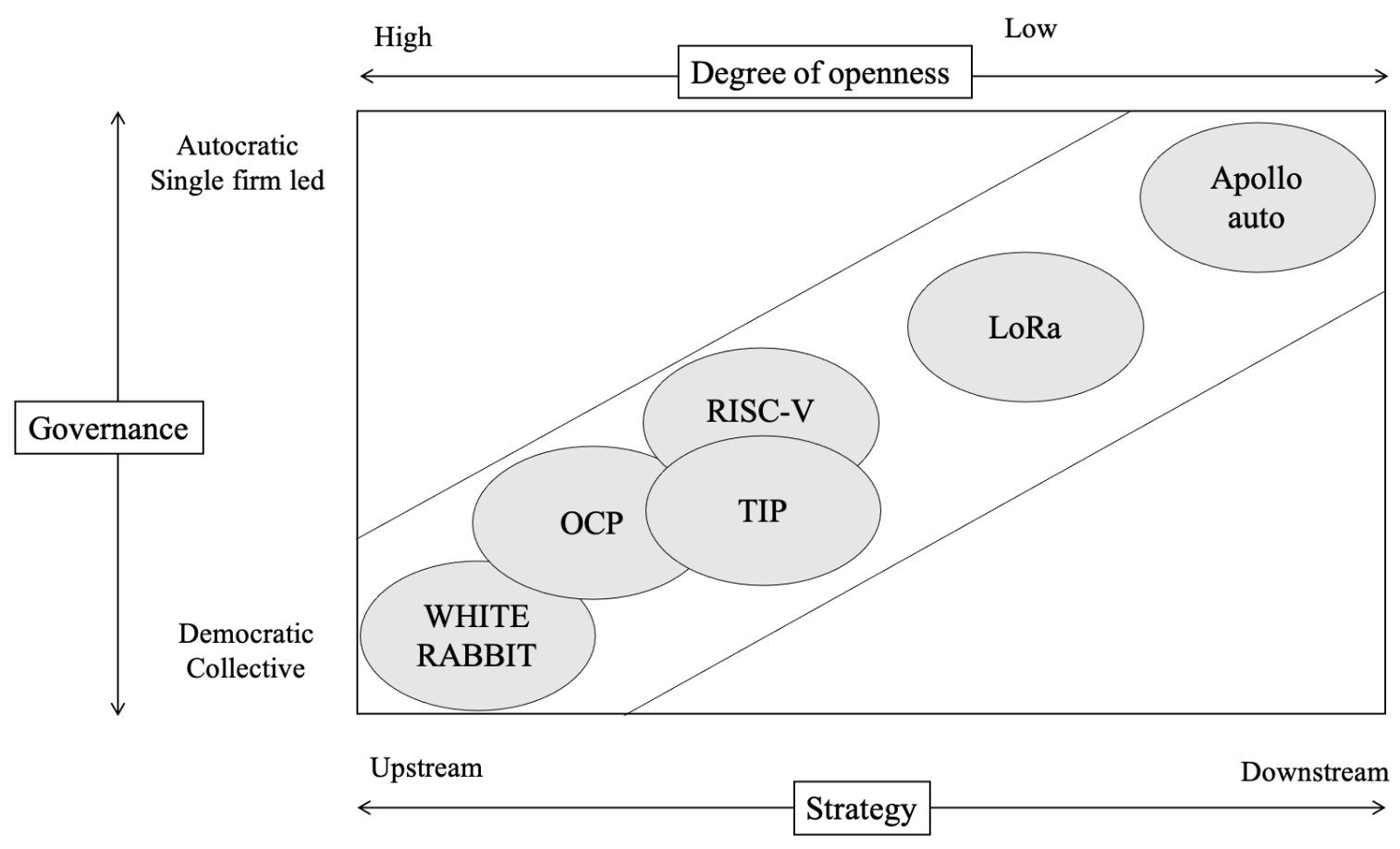

Figure 1. The six Ecosystems

for RISC-V, a high-profile board with some decision-making power ensures the integrity of the ISA to reassure adopters.

In Figure 1 below, we have positioned the six ecosystems along the main dimensions we have investigated.

\section{Conclusion}

The study of the cases presented in this research shows that HROSE can lower the development and dissemination barriers for complex hardware and software systems. By harnessing the power of collaboration across firms, such ecosystems obtain results that are beyond the reach of single firms. If successful, the momentum attained by such ecosystems can generate a wide array of service and product innovations. HROSE ecosystems allow to compete and collaborate on a large scale to create cost efficiencies and conquer new markets. A virtuous cycle of development is generated and learning and innovation are nurtured. The ecosystems we studied are run in a very disciplined manner and they emerged out of deliberate strategies. The solutions produced are robust and the ecosystems are actively managed. The success of these ecosystems depends fundamentally on the engagement of the partners, which is extensively favoured by the degree of openness and the governance practices.

\subsection{Main Contributions}

Our main contribution to the study of HROSE can be summarised as follow. First, an upstream strategy aimed at replacing supplier proprietary design with open substitutes requires a democratic governance and a degree of openness that maximize the attractiveness of the ecosystem. Second, a downstream strategy that aims at carving a space in new markets requires an autocratic governance and degree of openness that allow to attract partners while maintaining enough control to capture 
value.

One interesting finding that emerged out of the data collection process is the existence of dual ecosystem strategies. In the case of RISC-V and LORA entrepreneurial firms adopted a dual ecosystem. The creators of RISC-V launched the RISC-V foundation that curates the ISA and leads a wide ecosystem of firms that use and support the RISC-V. At the same time, they created an entrepreneurial firm (Sifive) with its own ecosystem of complementors that can contribute to design and manufacture processors. For LORA, the leaders of Semtech and Actility created an ecosystem of complementors around their respective firms to deploy loT solutions. Simultaneously, they established the LORA alliance, which promotes and supports development of the LoRaWAN standard. In line with Morris and Ferguson, (1993) these dual ecosystem approaches appear to enhance the overall value generated by the open system while maximizing the value captured by entrepreneurial firms that initiated the open system.

A second additional finding that emerged from the data collection are the difficulties encountered by open system adopters to integrate multiple assets for specific deployment and implementation. This was particularly noticeable for OCP, TIP and to a certain extent RISC-V. As disaggregation takes place, systems are decoupled into smaller assets that can be mixed and matched during the deployment and implementation of specific projects. From a supply chain point of view the integration activities such as the assembly, installation, maintenance, and servicing of systems deployed are typically performed by firms that own proprietary solutions against which open solutions compete. Integration capabilities are therefore scarce resources that can constrain the development of an open system. Early adopters of open systems tend to control the resources and capabilities needed to perform such integration while late adopters need to rely on the integration of external resources that emerge over time. However, integration capabilities appear to be scarce. They might be difficult to source or they can recreate lock-in situations.

\subsection{Managerial recommendations}

The analysis and comparison of the six ecosystems presented above provides valuable insights into how open source initiatives and more specifically how Hardware Rich Open Source Ecosystems can provide strategic opportunities to companies. We can distinguish two situations: (1) Launching a new ecosystem and (2) Joining an existing ecosystem.

\section{Launching a new ecosystem}

Launching an ecosystem requires an understanding of some specific dynamics. An upstream open strategy can be motivated by two different reasons. It can be motivated by the desire to accelerate the development of a promising solution or technology (WHITE RABBIT, OCP). In this case it is essential to turn the technology into an industry standard supported by multiple actors. However, in most cases it is motivated by the existence of bottlenecks or dependencies on the supply side that slow down developments and change some markets (TIP, RISC-V). In this case it is essential to join forces with others to create a viable alternative solution in the long term. With an upstream strategy, the focus is on creating an attractive ecosystem thanks to a high degree of openness. It is therefore recommended to adopt a democratic and inclusive governance process supported by a foundation. This foundation acts as an independent curator of the interfaces and assets; this limits the opportunity to reduce the degree of openness across the system so adopters and contributors are reassured. This foundation can also play a key role in fostering the collaborative development of assets and promoting open solutions.

Launching a downstream open strategy aims at carving a space for the founder of the ecosystem in a new market. Following the Google-Android success story this is often described as a latecomer 
strategy. It is a way to catch up with the competition. Apollo Auto is sometimes described as a strategy that can help Baidu close the gap with Waymo. It can also be regarded as a means to accelerate the development of a solution in a nascent market. Apollo Auto indeed accelerates the adoption of self-driving technology in China. This can require significant investment; Baidu announced in 2017 an investment fund of 1.5 billion dollars.

With a downstream strategy the focus is on creating an attractive ecosystem while capturing a share of the new market. Open assets are used to attract complementors and clients and proprietary solutions owned by the founders are used to create opportunities to capture a share of the generated value. In the case of Apollo Auto, proprietary components were not announced upfront, as the focus was on first growing the ecosystem. In the case of the Lora alliance the founders were able to benefit from their investment and proprietary solutions right from the start. This created tension as some members of the ecosystem had expressed concerns about the founder dominant position. However, this did not seem to prevent the ecosystem from growing. With a downstream strategy the founders should keep some control of the governance of the ecosystem. They need to keep their decision power to balance attraction and value capture. The Lora alliance is an interesting case as the foundation focuses on the promotion of the technology and solution, but does not decide on intellectual property rules. This shows that it is possible to adopt a rather centralised or even autocratic governance for some assets to capture value, while creating a more democratic governance around other assets for accelerated knowledge and technology dissemination activities to attract partners and clients.

\section{Joining an ecosystem}

Joining an HROSE is a challenging decision to make for many companies. Decision makers are often unacquainted with open strategies. Mentioning open source can even lead to some immediate emotional reactions. One to one collaboration can appear challenging so collaborating among hundreds is often perceived as a step into the unknown. It is difficult to assess the risks and opportunities and the consequence as to how the company will later operate as this can be difficult to anticipate. The first step to be taken is to characterise the HROSE strategy, governance, and intellectual property openness. The strategic intent of the founder should be aligned or complementary to that of the ecosystem leaders. If a firm are looking at regaining some degree of freedom in a constrained supply market, an ecosystem that has adopted an upstream strategy can be an attractive option. However, this means that you will need to take an active role within the ecosystem, and that you need to contribute to the development of the ecosystem if you wish some of the ecosystem partners to support you in the future. You need to develop a participation strategy in the ecosystem if you wish to leverage a maximum number of benefits out of it.

If you are looking at rapidly benefiting from nascent solutions and technology, joining an open source ecosystem will allow your company to rapidly experiment, access a broad array of valuable hardware and software and to develop your own solution or business. In such a scenario joining the ecosystem is a means to promoting it, to finding new partners and clients and to staying informed. With some downstream ecosystems, especially when founders have invested extensively, this can even create the impression that you have discovered a "treasure chest". You might not need to contribute as extensively as in the case of an upstream open source strategy. However, participating in an ecosystem is not without cost; resources and capital are needed to take part. It is important to monitor and manage dependencies that will appear over the longer term. Additionally, joining an ecosystem will change the way you source and supply and sometimes sell. These factors need to be anticipated. 


\subsection{Limitations and future research}

Comparative case studies, as they study in great depth a small number of phenomena, allow to generalise a limited number of findings while many valuable insights cannot be generalised. They nevertheless contribute to advance the theory or to highlight some phenomena worth further research. Our research does not escape such limitations. If our findings describe robust interplay between different types of open strategies, different modes of ecosystem governance, and diverse degrees of intellectual property openness for complex open systems, more research is needed on multiple fronts

We need to further understand the dynamics and the evolution of HROSE. First, longitudinal studies of specific ecosystems are needed to understand how they emerge, grow, develop and mature. Second, further investigation into what makes such ecosystems effective and efficient are needed. We have identified three key factors, but further research certainly would complement them. More specifically we would suggest studying how dual ecosystem strategies maximise both the overall value created by the open system and the value captured by entrepreneurial firms. Also, we should study the interplay between the emergence of integration capabilities and lock-in situations within such ecosystems. Finally, more research needs to be dedicated to enhancing our understanding regarding the implications of such ecosystems from an operations and supply chain management point of view as ecosystems are complemented by supply chains. This phenomenon remains largely unexplored but as digital technologies continue to be shaped by openness it offers significant opportunities for future research.

\section{References}

Alexy, O., West, J., Klapper, H., Reitzig, M., 2018. Surrendering control to gain advantage: Reconciling openness and the resource-based view of the firm. Strategic Management Journal 39, 1704-1727. https://doi.org/10.1002/smj.2706

Appleyard, M.M., Chesbrough, H.W., 2017. The Dynamics of Open Strategy: From Adoption to Reversion. Long Range Planning, Open Strategy: Transparency and Inclusion in Strategy Processes 50, 310-321. https://doi.org/10.1016/j.Irp.2016.07.004

Baldwin, C.Y., (2010). When open architecture beats closed: The entrepreneurial use of architectural knowledge. Harvard Business School Finance Working Paper, pp 10-063.

Balka, K., Raasch, C., \& Herstatt, C. (2014). The effect of selective openness on value creation in user innovation communities. Journal of Product Innovation Management, 31(2), 392-407.

Balka, K., Raasch, C., \& Herstatt, C. (2010). How open is open source?-software and beyond. Creativity and Innovation Management, 19(3), 248-256.

Boudreau, K., (2010). Open Platform Strategies and Innovation: Granting Access vs. Devolving Control. Management Science Vol. 56 No. 10, pp. 1849-1872.

Chesbrough, H.W., Appleyard, M.M., (2007). Open Innovation and Strategy. California Management Review Vol. 50 No. 1, pp.57-76. https://doi.org/10.2307/41166416

Colfer, L.J., Baldwin, C.Y., (2016). The mirroring hypothesis: theory, evidence, and exceptions. Industrial and Corporate Change Vol. 25, No. 5, pp.709-738

de Laat, P.B., 2007. Governance of open source software: state of the art. J Manage Governance 11, 165-177. https://doi.org/10.1007/s10997-007-9022-9 
Ferrer, G., (2010). Open architecture, inventory pooling and maintenance modules. International Journal of Production Economics, Integrating the Global Supply Chain Vol. 128 No 1, pp. 393-403. https://doi.org/10.1016/j.ijpe.2010.07.034

Frandsen, T., (2017). Evolution of modularity literature: a 25-year bibliometric analysis. International Journal of Operations \& Production Management Vol. 37 No. 6, pp.703-747. https://doi.org/10.1108/IJOPM-06-2015-0366

Gambardella, A., von Hippel, E., (2019). Open Sourcing as a Profit-Maximizing Strategy for Downstream Firms. Strategy Science Vol. 4 No 1, pp. 41-57. https://doi.org/10.1287/stsc. 2018.0075

Garud, R., Kumaraswamy, A., (1993). Changing competitive dynamics in network industries: An exploration of sun microsystems' open systems strategy. Strategic Management Journal Vol 14 No. 5, pp. 351-369. https://doi.org/10.1002/smj.4250140504

Garud, R., Kumaraswamy, A., Langlois, R.N. (Eds.), (2003). Managing in the modular age: architectures, networks, and organizations. Blackwell, Malden, MA.

Gawer, A., (2014). Bridging differing perspectives on technological platforms: Toward an integrative framework. Research Policy Vol. 43 No7, pp. 1239-1249. https://doi.org/10.1016/j. respol.2014.03.006

Gawer, A., (2011). Platforms, Markets and Innovation. Edward Elgar Publishing.

Gawer, A., Cusumano, M.A., (2014). Industry Platforms and Ecosystem Innovation. Journal of Product Innovation Management Vol. 31 No.3, pp. 417-433. https://doi.org/10.1111/jpim.12105

Gold, J., (2016). Microsoft's the top open-source contributor on GitHub. NETWORKWORLD. Retrieved June 15 $15^{\text {th }}, 2020$ from: https://www. networkworld.com/article/3120774/microsoft-sthe-top-open-source-contributor-on-github.html

Guertin, N. and Clements, P., (2010). Comparing acquisition strategies: Open architecture versus product lines. PROGRAM EXECUTIVE OFFICE INTEGRATED WARFARE SYSTEMS WASHINGTON DC.

Koren, Y., Hu, S.J., Gu, P., Shpitalni, M., (2013). Open-architecture products. CIRP Annals 62, pp. 719-729. https://doi.org/10.1016/j.cirp.2013.06.001

Legenvre, H., Kauttu, P., Bos, M. \& Khawand, R., (2020). Is Open Hardware Worthwhile? Learning from Thales? Experience with RISC-V, Research-Technology Management, 63:4, 44-53, DOI: https://doi.org/10.1080/08956308.2020.1762445

Langlois, R.N., Robertson, P.L., (1992). Networks and innovation in a modular system: Lessons from the microcomputer and stereo component industries. Research Policy Vol. 21 No. 4, pp. 297-313. https://doi.org/10.1016/0048-7333(92)90030-8

Lau, A.K., Yam, R. and Tang, E.P., (2010). Supply chain integration and product modularity: An empirical study of product performance for selected Hong Kong manufacturing industries. International Journal of Operations \& Production Management, Vol. 30 No. 1, pp.20-56.

Moritz, M., Redlich, T., \& Wulfsberg, J. (2018). Best practices and pitfalls in open source hardware. In International Conference on Information Theoretic Security (pp. 200-210). Springer, Cham.

Morris, C.R., Ferguson, C.H., (1993). How Architecture Wins Technology Wars. Harvard Business 
Review.

Muffatto, M., (1999). Platform strategies in international new product development. International Journal of Operations \& Production Management. Vol. 19 No. 5/6, pp. 449-460 https: //doi.org/10.1108/01443579910260766

Musk, E., (2014). All Our Patent Are Belong To You. Tesla. Retrieved on June 15 ${ }^{\text {th }}$, 2020 from: https://www.tesla.com/blog/all-our-patent-are-belong-you

O'Mahony, S., 2003. Guarding the commons: how community managed software projects protect their work. Research Policy, Open Source Software Development 32, 1179-1198. https: //doi.org/10.1016/S0048-7333(03)00048-9

O'Mahony, S., 2007. The governance of open source initiatives: what does it mean to be community managed? J Manage Governance 11, 139-150. https://doi.org/10.1007/s10997-007-9024-7

OSHWA. (2012, May 26). Definition (English). Retrieved November 1, 2019, from https: //www.oshwa.org/definition/

Powell, A. (2012). Democratizing production through open source knowledge: from open software to open hardware. Media, Culture \& Society, 34(6), 691-708.

Shapiro, C., Varian, H.R., (1999). Information rules: a strategic guide to the network economy. Harvard Business School Press, Boston, Mass.

Stam, W. (2009). When does community participation enhance the performance of open source software companies?. Research Policy, 38(8), 1288-1299.

Tushman, M.L. and Murmann, J.P., (1998), August. Dominant Designs, Technology Cycles, and Organization Outcomes. In Academy of Management Proceedings (Vol. 1998, No. 1, pp. A1-A33). Briarcliff Manor, NY 10510: Academy of Management.

Van der Bij, E. (2019). CERN Open Hardware Repository. CERN. Retrieved June $15^{\text {th }} 2020$ from: https://www.ohwr.org/projects/white-rabbit/wiki/wrcompanies

West, J., (2007). The economic realities of open standards: Black, white and many shades of gray. Standards and public policy, 87, pp.122. https://doi.org/10.1017/CBO9780511493249.004

West, J., (2003). How open is open enough?: Melding proprietary and open source platform strategies. Research policy, Vol. 32 No. 7, pp.1259-1285. https://doi.org/10.1016/S0048-7333(03) 00052-0

Zhang, J., Xue, G., Du, H., Garg, A., Peng, Q. and Gu, P., (2017). Enhancing interface adaptability of open architecture products. Research in Engineering Design, Vol. 28 No. 4, pp.545-560.. https://doi.org/10.1007/s00163-017-0264-5 


\section{Biographies}

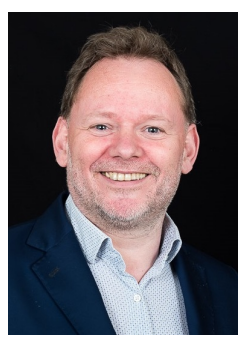

Hervé Legenvre. Hervé Legenvre, received his PhD degree in economic science from Université Paris Sud France, in 2011. Hervé worked for Renault Consulting and he later became Director of the European Foundation for Quality Management. He is currently Professor of Innovation at EIPM, The European institute of Purchasing Management. His research interest includes the role of suppliers in innovation, the development of the Internet of Things and open-source ecosystems. He is the Director of the Value Creation Observatory, the research lab of EIPM. Hervé awards and honors include Best competitive paper at IPSERA conference in 2016. He has been three times Best MBA professor of the Year at EIPM.

CRediT Statement: Conceptualization, Methodology, Formal analysis, Data Curation, Writing -Original Draft, Writing -Review \& Editing.

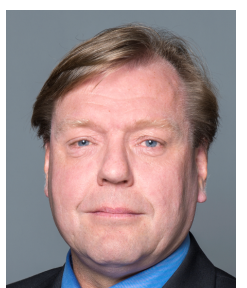

Ari-Pekka Hameri. Professor Ari-Pekka Hameri obtained his M.Sc. in 1987 and was conferred with the degree of Doctor of Technology in 1993 both in industrial economics from Helsinki University of Technology (HUT), currently Aalto University. He was the director of Institute of Industrial Automation, a research institute between industry and academia. He has been involved with numerous EU-funded and other international research projects dealing with new product development, operations and project management and supply chain management. He spent several years at CERN, the European Particle Physic Laboratory, Geneva, Switzerland, where he was supporting the building of the LHC accelerator. Since 2001 he has been full professor of operations management at University of Lausanne, Switzerland. He has performed over 100 supply chain audits in various industries, which include pulp \& paper, electronics, textiles, food and beverage, metal industry, watch, medical instrument, and some service sectors. He has also studied workflows and document processes related to new product development and project management. Prof. Hameri has published over 90 articles in international journals on production, project and supply chain management, and on industrial IT.

CRediT Statement: Conceptualization, Methodology, Formal analysis, Data Curation, Writing -Original Draft, Writing-Review \& Editing.

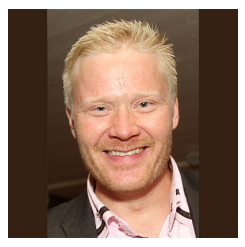

Pietari Kauttu. Pietari is the Vice-President of Consensus Capital LLC, and a senior industrial collaboration advisor of Helsinki Institute of Physics. His background is in R\&D\&l financial and procurement administration, and he has conducted research on novel technology collaboration mechanisms, in particular open source hardware, at CERN.

CRediT Statement: Conceptualization, Methodology, Formal analysis, Data Curation, Writing -Original Draft, Writing-Review \& Editing. 